\title{
Motivos y formas de las "burlas" infantiles
}

En el conjunto del Cancionero Popular Infantil Español (Poesía Lírica Popular de Tradición Infantil) hay un tipo especial de cantinelas que tienen como finalidad la manifestación, casi siempre pública, de una burla o mofa que dice un emisor y que es provocada por una actitud, un acontecimiento, un defecto físico, incluso un error o un simple descuido del receptor de la misma - al que, a menudo, se quiere provocar-, y que es quien además la sufre.

Los estudiosos que recogen este tipo de composiciones en sus antologías o colecciones les dan distintas denominaciones. Rodríguez Marín y Castro Guisasola - quienes, por cierto, recogen muy pocas- las llaman "pegas" y "dichos", respectivamente ${ }^{1}$. Bonifacio Gil habla de "burlas y burletas" "; Carmen Bravo-Villasante, aunque elude el término "burla", suele ofrecer algunas en sus colecciones, siempre tras el título general de "Retahílas de los juegos y fórmulas para la vida diaria" ${ }^{3}$. Otros las citan con denominaciones como "mentiras", "bromas", "patrañas" o "disparates". Muy pocos, las llaman explícitamente "burlas"; Gabriel Celaya ${ }^{4}$ es uno de ellos, y, como tales, incluye también los "trabalenguas".

Efectivamente, el "trabalenguas" puede entenderse como una burla más, porque de lo que se trata en él es de intentar que otro u otros repitan una cantinela - de evidente complejidad sonora- de la que el emisor que la propone domina su enunciado correcto. En ocasiones, el emisor hace la propuesta porque él mismo ya ha sido "burlado" antes del mismo modo. Así pues, el trabalenguas es una especie de juego "de pega o burla" basado en la complicación sonora de las expresiones sobre las que se

1 Francisco Rodríguez Marín, Cantos populares españoles (Madrid: Atlas, 1981), pp. 395 y ss.; y F. CASTRO GuISASOla, Canciones y juegos de los niños de Almería (Almería: Caja de Ahorros, 1973), pp. 91 y ss.

2 Bonifacio GIL, Cancionero Infantil (Madrid: Taurus, 2. ${ }^{\mathrm{a}}$ ed., 1974), pp. 40 y ss.

3 Cfr. Carmen Bravo-Villasante, Una, dola, tela, catola (Valladolid: Miñón, 1977), pp. 41 y ss.; China, china, capuchina (Valladolid: Miñón, 1981), pp. 5 y ss.; y Antología de la literatura infantil española (Madrid: Doncel, 1973), vol. III, pp. 77 y ss.

4 Cfr. Gabriel Celaya: La voz de los niños (Barcelona: Laia, 1981), pp. 103 y ss. 
construye la tonada: expresiones sin significado lógico, auténticos disparates a menudo, pero que ejercen un especial atractivo entre los niños y los adolescentes.

De todos modos, reconocemos que, a veces, no es fácil precisar las fronteras de estos géneros del llamado Cancionero Popular Infantil ${ }^{5}$; las dificultades que, en este sentido, solemos encontrar se derivan de la presencia de tonos que son propios de un tipo de composiciones en algunas tonadas que forman parte de otro u otros grupos. En el caso de las burlas, su "tono" más característico podemos percibirlo también en algunas adivinanzas (sobre todo en aquellas que, tras plantear el dilema terminan con expresiones del tipo "...Como no me lo aciertes, / no eres hombre", o "...el que no lo acertare / bien bobo es", o "...burro será / quien no lo adivine». También lo percibimos en algunas canciones que acompañan a juegos escenificados (como los de "la gallina ciega", "el escondite" o "el moscardón"). Gabriel Celaya supo captar muy bien la frecuente presencia de la burla en el conjunto de las tonadas infantiles:

Hasta los inocentes juegos de prendas se convierten en juegos de escarnio cuando se señala al que ha perdido lo que debe hacer para pagar su falta. Y no digamos cuando se salta "a la una anda la mula" o "a la pídola", porque ¿cuántas cosas no tiene que soportar el "burro"? No menos sarcasmo hay en las llamadas de "las cuatro esquinas" o de "la gallina ciega ${ }^{6}$.

En este último juego, por ejemplo, si quien "se queda" no acierta y, consiguientemente, no logra liberarse, escuchará una y otra vez la pregunta: "-Gallinita ciega, ¿qué has perdido?", a la que tendrá que responder siempre igual: "—Una aguja en un pajar", tras lo que acatará, con toda la tranquilidad que pueda, la misma orden: "—Date cuatro vueltas / y la encontrarás".

Pero, además del tono, también algunos contenidos dificultan la delimitación precisa de fronteras entre dos o más tipos de composiciones del conjunto de esta lírica popular. Veamos un ejemplo concreto: "Sana, sana, / culito de rana; / si no sanas hoy, / sanarás mañana". ¿Es una burla? ¿Es una retahíla que se interpreta como juego mímico en los primeros años del niño? El contexto en que se ejecuta es determinante para entenderla

5 En mi tesis doctoral Lírica popular española de tradición infantil, defendida en la Universidad Autónoma de Madrid (1986) y editada por la Universidad de CastillaLa Mancha (1994), propongo una clasificación que distingue los siguientes tipos de composiciones: 1. Nanas, 2. Adivinanzas. 3. Juegos mímicos y canciones escenificadas. 4. Oraciones. 5. Suertes. 6. Burlas y trabalenguas. (Cfr. op. cit., pp. 36 a 56).

6 G. Celaya, op. cit., p. 103. 
en un sentido o en otro; si el adulto, al tiempo que entona la cantinela, acaricia suavemente (con el fin de aliviarle el dolor) la parte del cuerpo que el niño pequeño se ha dañado (tras un golpe, rozadura o accidente similar), la entenderemos como un juego mímico. Pero, si el propio adulto o incluso entre niños más mayores un mismo compañero de juego, dirige esas palabras rimadas, con evidente intención de mofa, al niño que se lamenta, quejándose, de un pequeño golpe recién recibido $-\mathrm{y}$ que el emisor entiende que ha sido insignificante-, podemos entender la composición como una burla.

Lo mismo podríamos decir de otros casos, también muy conocidos, como el de "A la sillita de la reina"; cuando se practica con los más pequeños no deja de ser una inocente cancioncilla que acompaña un juego mímico, pero cuando son los mismos muchachos los que la interpretan puede convertirse en una verdadera broma pesada, en la que se burlan de quien cumple el papel de "reina", dejándole caer al suelo cuando menos se lo espera.

Precisamente, este tipo de razones son las que aportan sentido a las palabras, antes referidas, de Gabriel Celaya, en las que el poeta guipuzcoano señalaba la presencia de elementos burlescos en una parte importante de la totalidad del Cancionero Popular Infantil. No obstante, y dentro de él, la burla es un género que aporta sus propias peculiaridades; la más destacada, y a ella queremos referirnos en este trabajo, es la variedad ( $\mathrm{y}$, por lo tanto, riqueza) de los motivos que provocan, en cada caso, la emisión de la burla.

\section{LOS MOTIVOS}

De acuerdo a esos motivos, proponemos una clasificación de las burlas en cuatro grupos:

1. Burlas que acompañan, de modo exclusivo, a determinados juegos, siendo parte imprescindible de los mismos y que, en algunos casos, perderían sentido sin ellas.

Los ejemplos más significativos serían estos dos:

$$
\begin{aligned}
& \text { A la sillita la reina, } \\
& \text { que nunca se peina, } \\
& \text { un día se peinó, } \\
& \text { cuatro piojos se sacó }^{\text {}} \text {. }
\end{aligned}
$$

7 Todas las composiciones incluidas en el presente trabajo han sido tomadas de los trabajos del propio autor: Cancionero Popular Infantil de la provincia de Cuenca. 
Y:

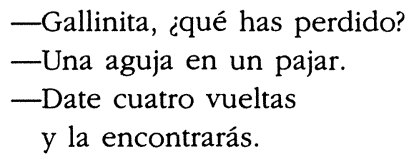

En el primero, como antes adelantábamos, quienes sostienen en brazos al chico o a la chica que representa el papel de "reina", lo sueltan de golpe dejándole caer al suelo. En el segundo, la burla forma parte del mismo juego, ya que se dice, de manera ritual, al comienzo del mismo.

2. Burlas que, provocadas por una acción o situación concretas, se han convertido en sonsonetes que se usan, ya siempre, en esas ocasiones. Veamos diferentes casos:

2.1. Cuando una persona se sienta en lugar que ocupa otra:

$$
\begin{aligned}
& \text { El que fue a Sevilla } \\
& \text { perdió su silla. } \\
& \text { El que fue a Aragón } \\
& \text { perdió su sillón }{ }^{8} \text {. }
\end{aligned}
$$

2.2. En respuesta a un insulto o comentario ofensivo:

El que lo dice lo es, con la cara al revés.

2.3. Cuando alguien lleva encima algo, puesto allí a propósito, sin darse cuenta de ello:

El burrito del teniente

lleva carga y no la siente.

2.4. Tras un corte de pelo:

¿Quién te ha pelado

que la orejas

te ha dejado?

(Lírica Popular de Tradición Infantil) (Cuenca: Diputación Provincial, 1991); y el ya citado Lírica Popular Española de Tradición Infantil. De ese modo se ha optado por una variante concreta - ya fijada por escrito- en los casos en que, por su transmisión oral, conocemos varias versiones de una misma tonada.

8 Una prueba de la riqueza de este tipo de composiciones es la existencia de versiones con las que se puede replicar a burlas tan concretas como ésta: "El que fue a Sevilla / perdió su silla. / Pero el que fue y volvió / la recobrón. 
2.5. Cuando alguien se queja tras un daño insignificante:

$$
\begin{aligned}
& \text { Sana, sana, } \\
& \text { culito de rana; } \\
& \text { si no sanas hoy, } \\
& \text { sanarás mañana. }
\end{aligned}
$$

2.6. Cuando alguien ha dado algo a otro (a veces, por error) y desea recuperarlo, puede escuchar como respuesta a su pretensión:

Santa Rita, Rita, Rita,

lo que se da, no se quita.

2.7. Cuando aparece alguien intentando, sin lograrlo, no ser reconocido; o cuando alguien percibe en el otro intención de engaño o mofa:

Te conozco, bacalao,

aunque vengas "disfrazao".

3. Burlas que el emisor recita tras provocar —él mismo- una situación que es la desencadenante de aquéllas.

Así, si demanda: "Dame la mano", cuando el destinatario se la va a dar, él mismo vuelve a intervenir para proferir la burla y dice: "-Toma el pie / que está más llano". O si pregunta "—iHas visto a la Dolores?", y su interlocutor, extrañado, le dice "—iA qué Dolores?", él podrá burlarse con la respuesta "LLa que tiene la cara / de mil colores". Frecuentemente, la provocación llega tras una pregunta que el propio emisor hace, como en este caso que hemos reseñado; pero, en otras ocasiones, el emisor es preguntado, lo que él aprovechará para entonar la burla que corresponda a la pregunta realizada; para "¿Dónde?":

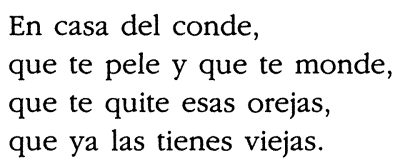

Para "¿Qué es esto?":

Uvas en cesto.

En este sentido, hay casos en que el emisor de la burla se aprovecha claramente de la bondad, de la ingenuidad o del descuido del destinatario: "Mira quién te llama", le dice el primero, ante lo que el segundo pregunta: "QQuién?", con lo que aquél puede proferir su expresión de burla: "El burro por la ventana" .

9 Existen diversas variantes: "-Mira quién te espera. / - ¿Quién?) / -El burro por la escalera». O: «iMira qué mancha de huevo! / ¡Toma, borrego!n (Esta expresión 
Otras veces, la burla se convierte en un verdadero disparate, por su completo sinsentido:

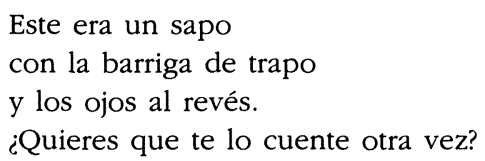

El destinatario responderá "Sín" o "no", pero dará lo mismo, porque el emisor, en cualquiera de los dos casos, repetirá la cantinela con una leve modificación al principio: "Yo no te digo ni sí ni no, / te digo que este era un sapo...".

Hay una burla, de gran difusión en España, que tiene su base en el doble significado de una de sus palabras:

$$
\begin{aligned}
& \text { Juan y Pínchame } \\
& \text { se fueron a bañar. } \\
& \text { Juan se ahogó, } \\
& \text { ¿quién quedó? }
\end{aligned}
$$

La respuesta, en apariencia sencilla, contiene una pequeña trampa que el destinatario — si no está listo- sufrirá en su piel; cuando responda lo obvio: "Pínchame", el emisor aprovechará para dar cumplida respuesta a su deseo y le pinchará.

4. Burlas que se dicen contra alguien concreto, provocadas por diversos motivos, aunque suelen estar relacionadas con la manera de ser, la constitución física, el estado emocional o determinados comportamientos o actitudes.

Es el grupo más numeroso, pues son muchos los casos concretos que provocan la emisión de una determinada burla. Veamos los más difundidos:

4.1. Contra los chivatos:

Acusica, Barrabás,

en el infierno lo pagarás.

4.2. Contra los que se enfadan fácilmente:
A. Mariquita está "enfadá".
E. Porque no sabe leer.
I. Porque no sabe escribir.
O. Porque el novio la dejó.
U. Borriquito como tú.

se acompaña con un golpe que el emisor da al destinatario cuando se dispone a mirar el lugar señalado por el primero, en el que, supuestamente, tendría la referida mancha. 
4.3. Contra los que dan mucha importancia al dinero:

Carmen, Carmona,

que por un ochavo

baila la mona.

4.4. Contra los cobardes:

Cobarde, gallina,

capitán de las sardinas.

4.5. Contra los llorones:

Llorica, manteles,

un cuarto me debes,

si no me lo das,

llorica serás.

Hay una variante que tiene su propio sentido: la que se dice contra quienes se refugian o protegen, ante cualquier pequeña circunstancia que pudiera resultarles adversa, en las populares y socorridas "faldas" de un adulto cercano, casi siempre el padre o la madre; sería ésta:

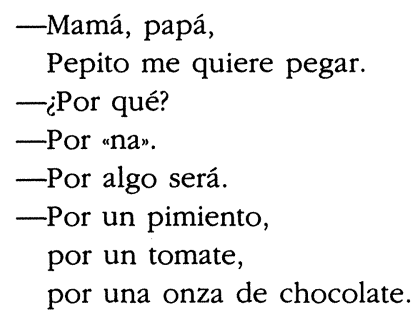

4.6. Contra los que son engañados fácilmente ${ }^{10}$ :
A los tontos de carabaña
se les engaña
con una caña,
menos a mí,
que soy de Madrid.

\footnotetext{
10 En este tipo de burlas, con toda probabilidad las de uso más frecuente, no se trata sólo de burlarse del que ha sido engañado, sino de demostrar —además- la frecuente tontuna que es propia del receptor de la mofa; el ejemplo más conocido es, sin duda, el más sencillo también: “A. E. I. O. U. / Borriquito como tú».
} 
4.7. Contra quienes sermonean y reprenden por cualquier motivo, por pequeño que sea:

Predícame, padre.

Por un oído me entra

y por otro me sale.

4.8. Contra los que tienen determinados defectos físicos:

a) Calvicie:

San Pedro, como era calvo,

le picaban los mosquitos,

y su madre le decía:

-Ponte el gorro, Periquito.

b) Cabeza grande:

$$
\begin{aligned}
& \text { Cabeza gorda, } \\
& \text { Napoleón, } \\
& \text { mató un chiquillo, } \\
& \text { por cabezón. }
\end{aligned}
$$

c) Joroba:

Rafalín, Rafaleta, cañón de escopeta, garbanzos tostados, anda, vete, jorobado.

En algún caso, nos encontramos con burlas que hacen referencia a varios impedimentos físicos al mismo tiempo y que, además, y dependiendo del contexto y del tono con que se interpreten, pueden ser portadoras de una gran crueldad:

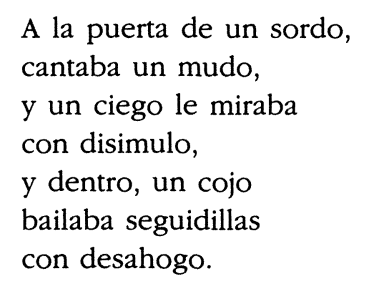

4.9. Contra determinados nombres propios de persona; veamos algunos ejemplos:

a) Antonio: 
Antonio, retonio, repica el pandero, sube a la torre y espanta a los perros.

b) Paco:

Paco, Pacorro,

quítate el gorro;

si no te lo quitas,

te doy un mamporro.

c) Juan:

Todos los Juanes son tontos. Los meten en un costal, los suben a la torre y los echan a volar.

d) María:

María, la pata fría, el culo caliente y el botijo de aguardiente.

e) Vicente:

f) Felisa:

Vicente, patente, pasó por el puente vendiendo patatas, ¡Jesús, qué baratas!

Qué risa con la tía Felisa, que se cagó en misa y lo limpió con la camisa.

g) Manuel:

Manolo, Pirolo, mató a su mujer, la hizo salchichas y la puso a vender.

b) Pedro:

Perico el de los Palotes se quiere meter torero, 


$$
\begin{aligned}
& \text { su padre no le deja } \\
& \text { y le tira de las orejas; } \\
& \text { se va por las callejas, } \\
& \text { se choca con las viejas; } \\
& \text { se va por los tejados, } \\
& \text { se choca con los soldados. }
\end{aligned}
$$

4.10. Otras. La variedad de motivos que provocan la emisión de "burlas" es $\tan$ grande, que el simple hecho de hablar o la habitual acción de mirar pueden ser respondidas con una de ellas; para el primero de los casos:

¡Qué hablas, cajón de tablas!

Para el segundo:

\section{¡Qué miras,}

cajón de migas!

En ocasiones - aunque bien es cierto que no muchas-, se incorpora a la burla algún personaje del mundo de la Literatura Infantil que, por alguna circunstancia especial que le es propia, encaja perfectamente en el sentido que con ella se quiere transmitir:

$$
\begin{aligned}
& \text { Pinocho fue a pescar } \\
& \text { al río Guadalquivir; } \\
& \text { se le cayó la caña } \\
& \text { y pescó con la nariz. } \\
& \text { A la vuelta de la esquina, } \\
& \text { nadie le conocía, } \\
& \text { porque tenía la nariz } \\
& \text { más larga que una vía }{ }^{11} \text {. }
\end{aligned}
$$

Hay, además, y excepcionalmente, burlas en las que el motivo de la mofa no se puede explicar sin el conocimiento previo del episodio histórico en el que tienen su contexto original; el ejemplo que a continuación incluimos (burla de los "falsos conversos" que se conserva, con notable vigor, en Andalucía) es un buen exponente, además, de la incorporación de hechos históricos, de significado concreto, al Cancionero Infantil:

Por la señal

de pito canal,

11 Recogida en la localidad conquense de Saelices. 


$$
\begin{aligned}
& \text { comí tocino, } \\
& \text { me hizo mal. } \\
& \text { Papuz, papuz. } \\
& \text { Amén, Jesús. } \\
& \text { Alza la pata } \\
& \text { y apaga la luz. }
\end{aligned}
$$

Gabriel Celaya explica que uno de los ejemplos más evidentes de cómo ciertos episodios nacionales, tanto sociales como políticos, pueden incorporarse al Cancionero Popular Infantil "[...] es el de los cristianos nuevos, que aún hoy, a los cinco siglos de la expulsión de los moriscos, gozan de vigencia” ${ }^{12}$. Francisco Rodríguez Marín, por su parte, afirmaba que en ellas

[...] encarecían la falsedad de su conversión, o ponderaban el haber de pasar por comedores de tocino y les suponían declarando que, a despecho de su antigua resistencia a comerlo, no les hacía daño; antes, si más de ello les diesen, más comerían: "Pater noster qui est in coelis, / pon la mesa sin manteles, / y el pan sin cortezón, / y el cuchillo sin mangón, / kirieleysón, kirieleysón" ${ }^{13}$.

Los niños, aunque no entendieran nada, se sentirían atraídos, como en otros casos del propio Cancionero (suertes o juegos mímicos), por la magia de la palabra poética. Precisamente, uno de los rasgos más llamativos de la burla es la frecuencia con la que nos encontramos expresiones sin significado lógico, que -en ocasiones- son verdaderos disparates, y que, sin embargo, han pervivido como parte sustancial de la composición, resistiendo el paso del tiempo.

Hay en la base de la poesía infantil, la escrita para niños, así como en el acervo tradicional anónimo y la creada por ellos, una definición común de sinsentido e irracionalidad [...] Se usa la poesía porque tiene en el disparate y en el juego su definición fundamental ${ }^{14}$.

Pero todo eso es propio, sin duda, del mismo lenguaje poético, que, como dice Vico, está en el origen de las culturas, porque los medios que son propios de ese lenguaje nacen para hacerse entender "quien ignora nombrar las cosas con voces propias, o bien habla con otro con quien no tiene vocablos concertados con que pueda traslucir su pensamiento" ${ }^{15}$.

12 G. Celaya, op. cit., p. 121.

13 Recogido por G. CElAYA, op. cit., p. 121.

14 Román LÓPEZ TAMÉs, Introducción a la Literatura Infantil (Oviedo: ICE de la Universidad de Santander, 1985), pp. 133 y 134.

15 Giambattista VICO, Principios de una ciencia nueva (México: Fondo de Cultura Económica, 1978), p. 219. 
La lengua primera, pues, aquélla en la que tiene su base la expresión infantil, está llena de imágenes y de metáforas, pero también de repeticiones, perífrasis, elipsis de diverso tipo, aliteraciones o interjecciones; procedimientos que, en su conjunto -y quizá por su constante impropiedad en relación con el lenguaje esperado-, parecen propios de un hablante que todavía no dispone de los medios más adecuados para su expresión ${ }^{16}$.

\section{LAS FORMAS ${ }^{17}$}

La burla es un género en el que no hay notorias complicaciones estructurales. Lo más normal es la estructura lineal de sus contenidos que, en algún caso, se apoya en elementos de corte narrativo, como la fórmula inicial, propia de los cuentos populares infantiles, del siguiente ejemplo:

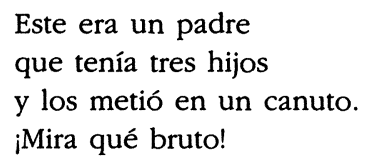

No obstante, en la organización de los contenidos de algunas burlas se perciben estructuras de otros tipos: "binarias" (casi siempre mediante la alternancia de "pregunta/respuesta"): "-Gallinita, ¿qué has perdido? / —Una aguja en un pajar (...)"; "paralelísticas": "El que fue a Sevilla / perdió su silla. / El que fue a Aragón / perdió su sillón"; o enumerativas": "A. / Mariquita está enfadá. / E. / Porque no sabe leer (...)"

Métricamente, la burla es una composición de corta extensión (en raras ocasiones sobrepasa los cuatro versos), en la que predomina el verso de arte menor (octosílabo, pentasílabo y hexasílabo, sobre todo), la rima regulada y la agrupación de versos en pareados ${ }^{18}$.

En cuanto a las figuras estilísticas y procedimientos estilísticos, cabría destacar la presencia, relativamente frecuente, de la ironía ("A la puerta de un sordo / cantaba un mudo [...]"; "El burrito del teniente / lleva carga y no la siente», etc.), así como un sistema metafórico notablemente varia-

16 Cfr. R. LÓPEZ TAMÉs, op. cit., p. 158.

17 Cfr. P. CERRILlo, Lírica popular española de tradición infantil (Universidad de Castilla-La Mancha, 1994), vol. I, pp. 473 y ss.

18 En algunos casos el pareado se apoya en un verso libre inicial. Con una frecuencia no muy acusada, algunas burlas se construyen en forma de cuarteta, de seguidilla o de tercerilla. 
do pero de escasa complejidad significativa: "cara de peseta", "nariz de escopeta", "la rabia te pica", "llorica manteles", "culito de rana", "capitán de las sardinas", "tontos de carabaña".

Es, por lo tanto, la burla un tipo de composición (en el conjunto del Cancionero Popular Infantil) en el que la rapidez y viveza con que se expresa la cantinela, la brevedad de su extensión y la sencillez de su construcción provocan que la sorpresa, que, en muchos casos, no se pretende intencionadamente, sea parte esencial del propio género. En cambio, sí es objetivo básico la chanza, incluso - a veces- la ridiculización del destinatario de la burla.

El cambio de costumbres, la disminución de espacios públicos para el juego infantil espontáneo, la aparición de nuevos tipos de relaciones sociales entre los miembros de una misma colectividad, la extensión y el desarrollo de los medios de comunicación que tienen en la imagen un incuestionable poder de convocatoria y de fascinación, han sido algunos de los motivos que han contribuido al debilitamiento de los mecanismos de transmisión de la Poesía Lírica Popular de Tradición Infantil; con ello, han disminuido las posibilidades de conservación, vivas en la cadena de lo oral, de estas obritas literarias.

La importancia del patrimonio cultural folclórico, así como sus aplicaciones para la evolución cultural de las sociedades son hechos reconocidos desde hace tiempo; de ahí, como afirma Luis Díaz Viana, que sea necesario:

[...] el conocimiento de las culturas tradicionales de las distintas regiones y la incorporación del mismo dentro del proceso de desarrollo e intercomunicación de las comunidades y países ${ }^{19}$.

La conservación de ese patrimonio es responsabilidad de todos los que forman parte de la colectividad propietaria del mismo; el cumplimiento de esa responsabilidad nos debe obligar a la recogida por escrito y a la fijación literaria de estas composiciones poéticas. La magia de su expresión, el placer del sinsentido, su componente lúdico o el ritmo de sus versos perderán, con toda probabilidad, parte de sus valores originales, pero, a cambio, garantizaremos su pervivencia a través del tiempo.

PEDRO C. CERRILlO TORREMOCHA

Universidad de Castilla La Mancha

19 Luis Díaz VIANA, "Folclore, nacionalismos y cultura", Revista de Folclore, núm. 62 (Valladolid, 1986), p. 39. 
El trabajo ofrece una caracterización de los contenidos de las burlas, un tipo de composiciones líricas que forman parte del Cancionero Popular Infantil español, así como una clasificación de las mismas, según los motivos que las provocan. El objetivo básico de la burla es la manifestación, casi siempre pública, de una expresión de mofa que un emisor dirige a un receptor; las causas que provocan esa expresión son variadas: una actitud, un hecho, un defecto físico o un simple descuido, entre otras.

The author offers in this paper a characterization of the content of the burlas - lyric compositions which belong to the repertoire of Spanish popular songs for children- as well as a classification of these pieces by the stimuli that prompt them. Expressed almost always in public, the burla is addressed by a speaker - its creator - to a receiver. The stimuli that incite it are various: any event will do, if not the receiver's physical defects, or his attitude or carelessness in any given situation. 